\title{
Article
}

\section{Defining Vulnerability: From the Conceptual to the Operational}

Keay, Scott and Kirby, Stuart

Available at http://clok.uclan.ac.uk/19620/

Keay, Scott ORCID: 0000-0001-6489-3010 and Kirby, Stuart ORCID: 00000002-3049-1248 (2018) Defining Vulnerability: From the Conceptual to the Operational. Policing, 12 (4). pp. 428-438. ISSN 1752-4512

It is advisable to refer to the publisher's version if you intend to cite from the work. http://dx.doi.org/10.1093/police/pax046

For more information about UCLan's research in this area go to http://www.uclan.ac.uk/researchgroups/ and search for < name of research Group>.

For information about Research generally at UCLan please go to http://www.uclan.ac.uk/research/

All outputs in CLoK are protected by Intellectual Property Rights law, including Copyright law. Copyright, IPR and Moral Rights for the works on this site are retained by the individual authors and/or other copyright owners. Terms and conditions for use of this material are defined in the policies page.

\section{CLoK}

Central Lancashire online Knowledge www.clok.uclan.ac.uk 


\section{Defining Vulnerability: From the Conceptual to the Operational}

\section{Authors: Scott Keay and Stuart Kirby}

\section{Abstract}

Whilst police agencies are increasingly being asked to assist vulnerable individuals, the concept of vulnerability, and how it how it should be policed, remains ambiguous. This study compares current academic thinking with the views and experiences of serving police employees. It presents a conceptual map to depict intersecting individual, social and environmental factors, to assist practitioners understand the concept of vulnerability, that also supports data sharing and partnership working. Further, it highlights the central importance of the police in a multi-agency triage process, signposting vulnerable individuals to the most appropriate service.

Keywords: police, vulnerable, vulnerability, policing demand, multi-agency.

\section{Introduction}

The nature of demand facing the police is changing. Whilst many categories of recorded crime are falling, police work is becoming more complex and this is particularly evident in increased calls surrounding public safety and welfare (Higgins \& Hales, 2016). As a visible and accessible 24-hour service, the police are generally viewed as the agency of last resort receiving a diversity of calls, of which crime is only $17 \%$ (College of Policing, 2015).

To respond to the increasing number of calls surrounding public welfare, tackling vulnerability through early intervention has emerged as a key theme in contemporary policing (BartkowiakThéron \& Asquith, 2012). Indeed, police forces are individually graded on how effective they are at protecting vulnerable people from harm by Her Majesty's Inspectorate of Constabulary (HMIC 2016). However, the way to do this remains ambiguous. Whilst some working definitions probably do exist (Rogers \& Colindris, 2015), HMIC (2016) noted that there is no 
accepted definition of vulnerability across the police forces of England and Wales and "forces continue to define a vulnerable victim in different ways" (2016:74). To compound this there is limited guidance as to who merits intervention. The purpose of this paper is to corral current academic thinking surrounding vulnerability and compare this with the views and experiences of serving police officers. Specifically, it aims to articulate what the concept of 'vulnerability' means in an applied police environment, and to discuss how this issue can be operationalised more effectively.

\section{Literature Review}

Defining vulnerability

There have been significant discussions regarding the concept of vulnerability in academia, especially from a bioethics perspective (Cunha \& Garrafa, 2016; Luna, 2009). A Scopus review using the search terms 'police' and 'vulnerable' or 'vulnerability', showed that social science academic journal articles on these terms had risen from five in 2001 to 52 in 2016.

At one level academics argue vulnerability can be viewed as a universal concept, inherent in all people, and core to the very nature of what it means to be human (Fineman, 2010). However, the subject eludes a precise or agreed definition, which means there is no consistency in its meaning or use. Some argue a definition is not appropriate (Wrigley and Dawson, 2016), with Fineman (2010:269) postulating that "variations amongst humans mean we have particular experiences of vulnerability", therefore a simple definition would deny its complexity. Similarly, Wrigley (2015) states defining vulnerability offers little to academia, as it does not explain the world.

Some resist a formal definition on wider, structural grounds. Green (2007:94) argues:

"Even if vulnerability could be ordered and measured, such research would probably still fall into the positivist trap of ignoring the social processes that both label people as victims and define their appropriate responses to harm caused". 
Others resist the term 'vulnerability' due to the connotations it constructs regarding the inherent weakness of specific groups (Chakroborti \& Garland, 2012), with such labelling generating stigma and negative effects (Noakes \& Wincup, 2004). Furthermore, some individuals considered vulnerable by the state, also challenge the label, learning to overcome or live with their vulnerability - such as a drug user overcoming addiction.

As 'vulnerability' is such a strong emerging theme, although inherent difficulties exist in composing a definition for it, the absence of a definition generates three specific problems for police practitioners. Firstly, UK police forces are now measured on their approach to tackle vulnerability. As such, there should be common agreement on what an appropriate standard should be. Secondly, police forces require some consistency of approach if they are to establish expertise and good practice. Finally, if the concept remains fluid there is a danger that the police will suffer mission creep, overlapping into services that may be more appropriately delivered by another institution. These issues demand the need for further definitional and operational clarity.

The Oxford English dictionary describes the term vulnerability as the exposure to being harmed or attacked. Harmon (2015:1) provides a similarly straightforward explanation, highlighting that it involves those individuals, “...easily harmed physically, mentally or emotionally. Vulnerable people are at a higher risk of being harmed". Similarly, Cops and Pleysier (2011:59), refer to vulnerability as "the perception of exposure to danger, a loss of control over the situation and a perceived inadequate capacity to resist the direct and indirect consequences of victimisation". Green (2012:92) states that vulnerability "is often used to express the level of risk posed to certain groups or individuals. The more vulnerable a person is, the more at risk they are of victimisation". Historically, a clear association exists with the plethora of studies that relate to victimisation, with the terms vulnerability and vulnerable people often linked to children and the elderly (Misztal, 2011). However, the terms are now being used on a much more regular basis, particularly across the public sector and in the media. Currently there is no accepted national definition that directs police activity. 
Initial attempts to identify those who are vulnerable has often highlighted specific categories. These have included: minority communities (Bartkowiak-Théron \& Asquith, 2014), those who suffer fear of crime (Radar et al., 2012), the poor (Lewis \& Lewis, 2014), those suffering inadequate housing provision (Palmer et al., 2012), social vulnerability to environmental hazards (Cutter et al., 2003), factors relating to victimisation (Green, 2007), including anti-social behaviour (Innes \& Innes, 2013). However, studies increasingly show that vulnerability is multi-dimensional, linked to a diverse range of individual and situational factors that can intersect. Rader, et al. (2012) highlight two main forms of vulnerability: physical vulnerability and social vulnerability. Whilst physical vulnerability refers to the physical characteristics of a person (e.g. gender and age), social vulnerability refers to social characteristics (e.g. race and socioeconomic status). Radar and Cossman (2011) also highlight the importance of health status / health disparity as an additional physical vulnerable factor. Innes and Innes (2013) further explained three broad areas of vulnerability to better understand the harmful impact on victims of anti-social behaviour, notably: physical, incidental and situational. This approach overlaps to some degree with previous descriptions of physical and social vulnerability.

A growing number of social dimensions can be associated with vulnerability. Some, explained as "primary dimensions" (Bartkowiak-Théron \& Asquith, 2012a:11), refer to age, culture, ethnicity, sexual and gender identities, as well as physical and psychological abilities. Social vulnerability, including class and socio-economic status, also appears as a common topic. Cutter et al. (2003) noted that social inequality was often a precursor to social vulnerability along with negative characteristics associated with specific environments. Innes and Fielding (2002) developed research on 'signal crimes'. This provided an indication of communities in decline and was often associated with communities that suffered a high fear of crime, a further topic that has generated academic research in vulnerability. Extending the research on environment it has also been noted that inequalities regarding the distribution of 
societal resources can also predispose people towards vulnerability and creates vulnerable populations (Nyamathi, 2007).

It is argued that placing people into 'vulnerability' categories can fail to recognise the wider social context as well as specific marginalised groups, such as the homeless (Bartkowiak-Théron and Corbo Crehan, 2010). Luna (2009) argues there appears to be a growing list of subpopulations regarded as vulnerable. However, many commentators argue that vulnerability does not occur in silos (Asquith, et al., 2016), and further understanding should be generated as to how these issues intersect with each other (Bartkowiak-Théron \& Asquith, 2012b). Those who are truly vulnerable, including marginalised and hard to reach groups, often exhibit a range of vulnerabilities that intersect with each other (BartkowiakThéron \& Asquith, 2012b; Misztal, 2011). For example, research shows that individuals who suffer adverse childhood experiences (Wager, 2015), are more likely to experience later physical and social vulnerabilities that have a detrimental impact on their health. Of course the danger of this research is that vulnerability can be all encompassing and 'vulnerable people' becomes the new term for "disadvantaged members of society" (Bartkowiak-Théron \& Asquith, 2012b:43). As such, identifying vulnerability is only one side of the challenge facing the police practitioner, the other side is how to respond to it. This is the direction this article now turns.

How should the police respond to vulnerability?

If the police are to become adept at identifying and prioritising vulnerability the next challenge is how vulnerability should be responded to. Commentators agree that vulnerability should be tackled in a multi-disciplinary and multi-agency way. Bartkowiak-Théron and Asquith (2016) note that criminology and health studies have diverged conceptually, and yet vulnerability is an issue that straddles a number of different disciplines. When health and police professionals work together operationally it is generally to safeguard individuals, rather than engaging in 
strategic collaboration to develop preventative measures, policy or procedures (BartkowiakThéron \& Asquith, 2017).

The diversity, complexity and cross-disciplinary nature of vulnerability certainly points to the needfor a collaborative approach. Although multi-agency initiatives are diverse, the majority are based upon three common principles: information sharing; joint decision-making; and coordinated intervention (Home Office, 2013). Unfortunately, there is considerable evidence to show multi-agency engagement suffers from implementation failure (Kirby, 2013). Paterson and Best (2015) argue that conflicting agency priorities often leads to confusion, with police officers become embroiled in competing policies. Concerns are also voiced in relation to the weaknesses in police training due to the negative effects of persistent stereotypes (Bartkowiak-Théron \& Asquith, 2012b), and police profiling (Cooper, 2015). Caution is also raised concerning the impracticality of training the police in all areas of social care, as well as pushing officers into a labyrinth of protocols and policies (Bartkowiak-Théron \& Asquith, 2012b).

The complexity of multi-agency working is evident in relation to sexual crime and mental health crisis, however it is expected to emerge increasingly in lower level public welfare incidents. There appears to be a consensus that police and criminal justice partners need to take time to understand vulnerability to deal with the challenge more effectively, rather than merely reacting to its symptoms (Bartkowiak-Théron \& Asquith, 2012b). Aside from brokering the development of personal resilience, others have highlighted the importance of tackling the root causes of vulnerability so communities can be equipped to cope with future issues (Lewis \& Lewis, 2014). This is because personal (or physical) vulnerability can be exacerbated through social conditions (e.g. social and environmental vulnerability) (Innes \& Innes, 2013).

Further, structural or systematic concerns have also been voiced. Williams et al. (2009) found that vulnerable victims of sexual and violent crime have often failed to progress through the criminal justice system. Similarly, concerns about generating unintended consequences 
have also been made when highlighting the negative ramifications emanating from the MacPherson inquiry in 1999. As Bartkowiak-Théron and Asquith (2014:89), point out,

"[T]he policies and practices to emerge since the MacPherson report have taken race and cultural difference as a template for the development of an ever-increasing number of siloed responses to vulnerability in the policing process."

In summary, the concept of vulnerability is an emerging and significant area of police demand. However, transforming this concept into operational practice is difficult to navigate. It can be argued that every interaction with the police is due to some form of vulnerability (Asquith \& Bartkowiak-Théron, 2016), which raises the question as to who is vulnerable and whether vulnerability is the norm or the exception? If so, how should the police prioritise the most vulnerable in society? The basis of these questions was explored with practitioners.

\section{Method}

This study used a discussion group, which was a useful means to develop knowledge about how practitioners respond and deal with vulnerability. This developed additional material, through open discussion, that could have been missed using a series of interviews (Ritchie \& Lewis, 2003). The workshop commenced with a ten-minute introduction by the lead researcher regarding the aims of the study, which were based on the literature review. The introduction included statistics from the force where the study took place regarding frequency and type of calls for service.

\section{Participants}

A total of 28 police officers and non-operational police staff, were invited to engage in this study and fifteen responded. They were selected based on their current role that involved dealing with vulnerable people and situations and although not paid to participate in the study 
they could attend during working hours. All participants had a minimum of five years' service in the Force and a minimum of 12 months in their current role. The discussion group incorporated four police staff roles (two males and two females) and 11 police officers ranked from constable (three females), Sergeants (two males and two females) and Inspectors (four males). These included representatives from the:

- Early Action Team: a specialist team who deal with repeat callers who, due to vulnerability, call the police to aid them. This can involve confused members of the public, those suffering mental illness, the elderly and those with learning difficulties;

- Community Safety Department: who deal with community based concerns;

- Public Protection Unit: who deal with children and adults who are vulnerable to sexual exploitation or physical abuse;

- Integrated Offender Management Unit: who assist repeat offenders desist from further offending;

- General uniformed response: who are first responders to people in crisis.

Data collection

Five questions were posed at the workshop. The questions used to probe the conclusions from the literature review were:

1. What is vulnerability?

2. Who is vulnerable?

3. Why should the police respond to vulnerability?

4. How should the police respond to vulnerability?

5. What evidence-base is required (in order to effectively manage vulnerability)?

These were verbally introduced to the participants by the lead researcher. The participants were instructed to visit the five separate workstations around the room, where each of these questions was replicated on a large piece of paper. The workstations were arranged in the 
same order as the questions. Participants were then asked to respond to each question by writing comments on 'post-it' notes and sticking them to each specific workstation. To maintain anonymity the participants were asked not to write their name or anything that could identify them. They did not have to go through the workstations in any particular order. This ensured that movement between each station was free flowing and not congested.

An hour was provided for this task, which appeared adequate as all participants had visited each workstation and had stopped writing by the time they were recalled into plenary. A summary of these comments have been included in column two of table 1 (in the results section). The group then reformed to discuss each of the headings, to further explain their comments and to consider further opinions based upon what they had heard from the other participants. Additional material was collected by the lead researcher but subject details were not taken. Some quotes from the later session are included in the third column of table 1.

\section{Limitations}

The limitations of this study centre on the size of the focus group. Only one focus group from one UK police force was used for this study and the participation response rate was $54 \%$. Clearly, this limits the wider generalisation of any key findings. It does, however, help direct potential future study to develop a wider understanding of vulnerability from different forces. For example, would there be a difference in approaches towards vulnerability between smaller forces and the larger metropolitan forces?

\section{Results}

The statistical data provided for the introduction was gathered from the police force's corporate analysis department. The data showed that on an average day the Constabulary receive 551 emergency calls (999), 2251 non-emergency calls, make 94 arrests, deal with 18 missing from home enquiries, and have 255 crimes reported. Further analysis showed that they make 52 
referrals to other agencies for individuals who are marked as vulnerable (25 for vulnerable adults and 27 for vulnerable children).

Provision of the statistical data allowed the study group to contextualise the volume of calls and subsequent referrals that were regarded as involving vulnerable people. There was unanimous agreement that the term vulnerability (in a policing context) was difficult to explain. As such, the term was subjective and created confusion amongst practitioners, who provided different opinions as to what it was and how the police should respond to it. Practitioners explained there was a lack of strategic direction in relation to the concept and this affected the development of appropriate approaches, when responding to demand. During the discussions practitioners highlighted they viewed their task as dealing with 'person(s) who require specialist attention or support'. Practitioners were unanimous in thinking anyone could be vulnerable and this simple fact created confusion as to who should be targeted. Whilst practitioners said they saw assisting the most vulnerable as a core policing role, some pointed out that they felt they should not encroach on the role of other agencies. The practitioners also agreed on the two main topics that required further clarification: understanding vulnerability and how to police vulnerability. A summary of these discussions is outlined in table 1 (below). 
Table 1. Focus Group Results: Key points in thematic analysis

\begin{tabular}{|c|c|c|}
\hline Question & Summary & Quotes \\
\hline $\begin{array}{l}\text { What is } \\
\text { Vulnerability? }\end{array}$ & $\begin{array}{l}\text { It is unclear as there are changing } \\
\text { circumstances. It is dependent upon the } \\
\text { context of the situation in which there are } \\
\text { many factors. Vulnerability is laden with } \\
\text { connotations and is too much of a } \\
\text { subjective term to warrant any significant } \\
\text { direction for policing. }\end{array}$ & $\begin{array}{l}\text { "How someone feels at the time." } \\
\text { "Anyone can be vulnerable depending } \\
\text { on changing circumstance." } \\
\text { "Being at a disadvantage to peers." } \\
\text { "Lack of capability to deal with your } \\
\text { situation." }\end{array}$ \\
\hline Who is vulnerable? & $\begin{array}{l}\text { Everyone can be vulnerable at any point } \\
\text { of their life. Certain groups are more } \\
\text { prone to vilnerability than others: such as } \\
\text { those with mental health issues, children, } \\
\text { people with low self-esteem, people with } \\
\text { dependency (alcohol or drugs), and those } \\
\text { from different cultures. }\end{array}$ & $\begin{array}{l}\text { "Everyone. Anyone can be." } \\
\text { "Different types of vilnerability affect } \\
\text { people differently." } \\
\text { "Those with a factor that impairs their } \\
\text { ability to identify risk or threat, e.g. } \\
\text { those with mental health issues." } \\
\text { "People with low self-esteem." }\end{array}$ \\
\hline $\begin{array}{l}\text { Why should we } \\
\text { police vulnerability? }\end{array}$ & $\begin{array}{l}\text { Protecting the public from harm, keeping } \\
\text { the public safe, preventing crisis and } \\
\text { because it is the police core business. } \\
\text { However, some participants challenged } \\
\text { whether this was perhaps mainly a role } \\
\text { for other services. }\end{array}$ & $\begin{array}{l}\text { "To prevent it and improve outcomes } \\
\text { for everyone." } \\
\text { "Prevent a cycle of problems." } \\
\text { "As part of collaborative working." } \\
\text { "Because it is core business." } \\
\text { "We shouldn't always police it." }\end{array}$ \\
\hline $\begin{array}{l}\text { How should the } \\
\text { police do it? }\end{array}$ & $\begin{array}{l}\text { Vulnerability cuts across all public } \\
\text { services and agencies must work in } \\
\text { partnership to tackle issues. There is a } \\
\text { tendency to work in silos and that this } \\
\text { hampered any joined up action across } \\
\text { public service agents. }\end{array}$ & $\begin{array}{l}\text { "Stop working in silo's and work in } \\
\text { partnership with other agencies." } \\
\text { "Use of neighbourhood policing teams } \\
\text { to support communities." } \\
\text { "Flag up to appropriate services." } \\
\text { "By building self-resilience." }\end{array}$ \\
\hline $\begin{array}{l}\text { What evidence-base } \\
\text { do we need? }\end{array}$ & $\begin{array}{l}\text { There needs to be a consensus as to } \\
\text { what vulnerability is and whose role it is } \\
\text { to respond to a defined vulnerability. } \\
\text { There needs to be a collective } \\
\text { understanding of what the issues are } \\
\text { surrounding the vulnerability. }\end{array}$ & $\begin{array}{l}\text { "Agree on what vilnerability is." } \\
\text { "Clear aims to establish a reliable } \\
\text { measure." } \\
\text { "What works: what interventions have } \\
\text { the greatest impact." } \\
\text { "Knowledge of what support is } \\
\text { available." } \\
\text { "Collective understanding of what } \\
\text { issues in a person's life are." }\end{array}$ \\
\hline
\end{tabular}




\section{Discussion}

This paper aimed to compare current academic thinking surrounding the term vulnerability with the views and experiences of serving police officers and police staff. The recent focus of attention is that of policing vulnerability (Bartkowiak-Théron \& Asquith, 2014). Although the term vulnerability is becoming pervasive in policing, the lack of defining it is illustrated in many ways. Results from the focus group go some way to demonstrate this. Focus group data showed that there were different perceptions of vulnerability. Whilst the focus group noted that 'anyone can be vulnerable', the summary regarding 'what is vulnerability' was that the term itself was too subjective to provide significant direction for local policing. Possibly because vulnerability is often spoken about as a "taken-for granted term" (Stanford, 2012:20). Furthermore, two other issues were highlighted by the focus group. Firstly, the focus group noted that the context of vulnerability was often situational and may be the result of a number of factors that can vary from case to case. Interestingly, Paterson and Best (2015) note that vulnerability is context specific but tends to be defined by "deficit frameworks that view individuals as marginalized [sic] or disadvantaged and requiring immediate intervention" (2015:152). Secondly, the group argued that there needs to be a consensus as to whose role it is to respond to vulnerability. It was noted that public services can work in silos but must work more closely in partnership to tackle vulnerability. Bartkowiak-Théron and Asquith (2016) argue that the police and health agencies need to work more closely in developing collaborative policies. Whilst Paterson and Best (2015) add to the debate that effective partnerships are needed to tackle issues such as vulnerability but they do not necessarily have to involve statutory bodies.

The practitioner group suggest that policing vulnerability can be collapsed into two main areas: understanding vulnerability and responding to it (which includes prioritising different aspects of vulnerability and responding in the most effective manner). To conduct the latter effectively requires a firm foundation from the former. How then can this literature review, coupled with the practitioner group, assist in this challenge? 
The views of practitioners were consistent with academic research in describing the different facets of vulnerability and its multi-layered nature. This extends Luna's (2009) perception of vulnerability factors as 'layers', rather than distinct categories or subpopulations, which echoes approaches made in health research (Bircher and Eckhart, 2017). With this in mind, figure 1 is proposed as a conceptual map to help understand vulnerability by a police practitioner audience.

Figure 1. Prominent attributes influencing potential vulnerability.

This conceptual map is not an exhaustive collection of vulnerable traits or characteristics. The cited research provides an example of when these traits have been identified as a prominent attribute in the literature.

Attributes of physical / personal:

- Gender (Cops \& Pleysier, 2010).

- Age (Radar, et al., 2012).

- Health (Bartkowiak-Théron \& Asquith, 2016).

- Sexuality (Wager, 2015).

- Physical abilities (Roulstone, etal. 2011).

- Psychological abilities (BartkowiakThárnn \& $\Delta c$ cuith 2n16)

\section{Attributes of social / familial:}

- Race (Radar \& Cossman, 2011).

- Class (Fineman, 2012).

- Socio-economic status (Sparks, 1981).

- Demographics (Cutter, 2003).

- Maternal attachment (Mack et al., 2007).

- Role in relationship/family (Mack et al $2 n \cap 71$
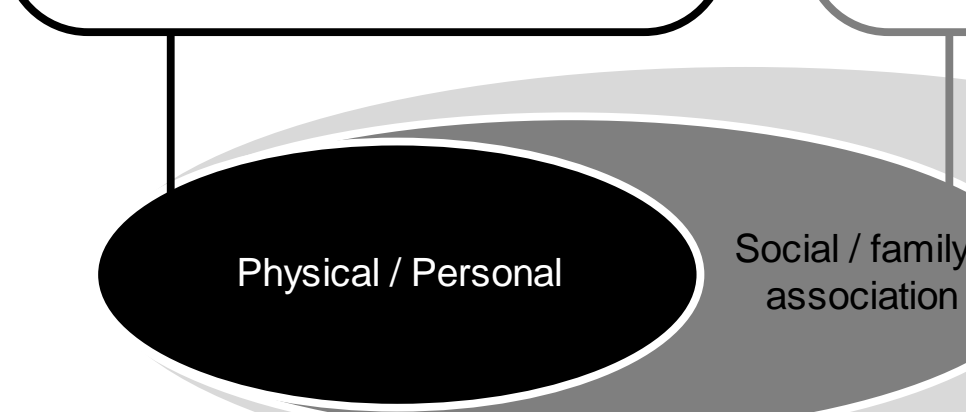

Social / family / association
Environmental / situational

Attributes of environmental / situational:

- Locality (Innes \& Fielding, 2003).

- Neighbourhood characteristics (Innes \& Innes, 2013).

- Deprivation (Lewis \& Lewis, 2014).

- Signal crimes (Innes \& Fielding, 2003).

- Impact of physical layout (Cutter, 2003).

- Repeat victimisation (Farrell \& Pease, 1993).

- Social isolation (Mechanic \& Tanner, 2007).

- Housing (Palmer, 2012). 
The first category relates to the individual, where physical and personal characteristic can be associated with vulnerability. The second relates to wider social and familial factors relating to relationships and a person's place in society. Finally, the third category relates to wider environmental or situational factors. These issues are situational, rather than dispositional and are therefore (potentially) the easiest to change. This conceptual map provides a dynamic quality, illustrating the relationship between a person, wider relationships and situational context (Luna, 2009). The factors presented in the map are by no means exhaustive or the only means of conceptualising the process. The purpose of it is to highlight potential characteristics or attributes that can influence, be present in, or exacerbate vulnerability. Vulnerability can be one or more attributes within a 'layer', or multiple ones across a variety of layers (Luna, 2009), also noted by Bartkowiak-Théron and Asquith as "cross-sectional" (2012b:46) vulnerability. However, it should be pointed out that this is a positivist approach to vulnerability, which is more applicable to practitioners; it does not encompass wider structural notions of vulnerability, created through the unintended consequences of government policy or systems.

A conceptual map of this type encourages the police to maintain focus upon behaviours and trends within these layers and encourages collaboration with other agencies around data sharing and partnership working. It reduces the danger of ignoring individual need allowing people to be prioritised on merit, in terms of harm. So, for example, an individual who is suffering mental illness, who is homeless and suffering domestic violence can be so prioritised. This supports Paterson and Best (2015) who argue people should not be placed into contentious subpopulations of vulnerability and be left there awaiting some form of service. People in subpopulations may have multiple vulnerabilities, which can vary from person to person (Luna, 2009).

The map also provides some clarity to understanding how vulnerability should be tackled. A multi-agency approach to tackling underlying policing issues has long been highlighted (Schuller, 2013), with a growing emphasis towards health and wellbeing. Schuller 
(2013) noted that perhaps crime is a question of health and argued that there should be a convergence of health disciplines and that of criminal justice and community safety. Akers and Lanier (2009) have also argued for a similar convergence, but refer to it as one of epidemiological criminology, stating that members of public health and criminal justice disciplines often work with the same marginalised populations (e.g. people at high risk of drug use, health issues, etc.). There are many links between health and crime (Bartkowiak-Théron \& Asquith, 2017) with both issues costing millions to public services and the wider community. Crime is associated with social disorganisation, low social capital, deprivation, and health inequalities. The same social and environmental factors which predict geographic variation in crime rates may also be relevant for explaining community variations in health and wellbeing (Kawachi, et al., 1999). Therefore, it is argued that vulnerability is synonymous with the 'needs' of an individual.

If the police are to become more proactive in reducing demand and harm, then they must assist in tackling the underlying causes of vulnerability, but what should be their role? Fineman, (2010), argued that although everyone has needs, the needs of some are greater than others. It therefore appears logical that as the police are often called to assist in dealing with the symptoms of these issues, they can be part of the solution by helping to tackle the root causes (Goldstein, 1979), that generate and exacerbate vulnerability (Bartkowiak-Théron \& Asquith, 2017). Specifically, the police are often in a good position to lead the triage process, identifying need and (when not able to find the solution themselves) act as brokers for the most suitable service (Bartkowiak-Théron \& Asquith, 2012b). As such, they could signpost individuals to the right services to step them down from their crisis and helping to prevent them becoming a repeat service user.

The conceptual map shown earlier (figure 1) provides a method of understanding and diagnosing need, which is a precursor to tailoring services to meet that need. Whilst in theory a convergence between disciplines (Bartkowiak-Théron \& Asquith, 2017) is the best public sector approach in tackling complex factors that underpin vulnerability (Rogers \& Coliandris, 
2015), operationally this may be difficult due to the variety of policy and protocols adhered to by different agencies. The police often act as an informal triage to refer and signpost individuals to other services. In an era of austerity, it is beneficial to formalise these issues, rather than allowing decision inertia to create confusion over institutional responsibility and accountability. The danger remains that this significant and new approach to policing will stumble onwards without strategic clarity, leading to inevitable mission creep, with the police drifting into new areas of business without fully understanding the cost or implications.

\section{Conclusion}

This article highlights an emerging area of police demand in the UK, relating to tackling vulnerability. A review of the academic literature, supported by a practitioner group, shows the concept of vulnerability is shrouded in ambiguity, and there is little guidance for operational policing.

It is accepted that individuals who require assistance from the police, are generally experiencing some level of vulnerability. The HMIC (2016:72) note that, "vulnerability continues to grow and accounts for a considerable amount of police time in responding to calls for service". To reduce this vulnerability (and public sector demand), the police need to understand the 'needs' of those seeking support. It can be argued frontline officers see the symptoms of crisis, experienced by vulnerable people, on a day-to-day basis. Those individuals that officers do not have the skills or mandate to provide sustainable solutions for, they can signpost to other services. To operationalise this triage process the police need an increased knowledge base in relation to vulnerability, together with more effective systems to refer individuals. A conceptual map is presented in this paper that corrals existing studies into intersecting individual, social and environmental factors that can be used by police practitioners in a triage process for those they find in crisis. This should support data sharing and partnership working. Without formalising this role there is a danger that confusion will continue, leading to unintended consequences. 


\section{References}

Akers, T. and Lanier, M. (2009). 'Epidemiological Criminology”: Coming Full Circle.' In American Journal of Public Health, 99(3): pp. 397-401.

Asquith, N., Bartkowiak-Théron, I. and Roberts, K. (2016). 'Vulnerability and the Criminal Justice System' (Guest editorial). In Journal of Criminological Research, Policy and Practice, 2(3): pp. 161-163.

Bartkowiak-Théron, I. and Asquith, N. (2017). 'Conceptual Divides and Practice Synergies in Law Enforcement and Public Health: Some Lessons from Policing Vulnerability in Australia.' In Policing and Society: An International Journal of Research and Policy, 27(3): pp. 276-288.

Bartkowiak-Théron, I. and Asquith, N. (2014). 'Policing Diversity and Vulnerability in the PostMacpherson Era: Unintended Consequences and Missed Opportunities.' In Policing, 9(1): pp. 89-100.

Bartkowiak-Théron, I. and Asquith, N. (eds) (2012a). Policing Vulnerability. Sydney: Federation Press.

Bartkowiak-Théron, I. and Asquith, N. (2012b). 'The Extraordinary Intricacies of Policing Vulnerability.' In Australasian Policing: A Journal of Professional Practice and Research, 4(2): pp. 43-49.

Bartkowiak-Théron, I. and Corbo Crehan, A. (2010). A new movement in community policing? From community policing to vulnerable people policing. In Putt, J. (2010) Community Policing in Australia, Research and Public Policy Series 111. Australian Institute of Criminology.

Bircher, J. and Eckhart, H. (2017). Will the Meikirch Model, a New Framework for Health, Induce a Paradigm Shift in Healthcare? [Online access: https://www.ncbi.nlm.nih.gov/pmc/articles/PMC5383372/].

Bolling, K. Grant, C. and Sinclair, P. (2007). British Crime Survey of England and Wales 
2006/07. [Online access: http://www.esds.ac.uk/doc/5755/mrdoc/pdf/5755techreport_vol2].

Chakraborti, N. and Garland, J. (2012). 'Reconceptualizing Hate Crime Victimization through the Lens of Vulnerability and 'Difference'.' In Theoretical Criminology, 16(4): pp. 499-514.

College of Policing. (2015). 'College of Policing Analysis: Estimating Demand on the Police Service.' [Online access:

http://www.college.police.uk/documents/demand_report_21_1_15.pdf].

Cops, D. and Pleysier, S. (2011). "Doing Gender' in Fear of Crime: The Impact of Gender Identity on Reported Levels of Fear of Crime in Adolescents and Young Adults.' In British Journal of Criminology, 51(1): pp. 58-74.

Cooper, F.R. (2015). 'Always Already Suspect: Revising Vulnerability Theory.' In North Carolina Law Review 93(3): pp. 1339-1380.

Cunha, T. and Garrafa, V. (2016). 'Vulnerability: a Key Principle for Global Ethics.' In Cambridge Quarterly of Healthcare Ethics, 25(2): pp. 197-208.

Cutter, S., Boruff, B. and Shirley, W. (2003). 'Social Vulnerability to Environmental Hazards.' In Social Science Quarterly, 84(2): pp. 242-261.

Farrell, G., and Pease, K. (1993). 'Once Bitten, Twice Bitten: Repeat Victimization and its Implications for Crime Prevention'. Police Research Group, Crime Prevention Unit, Paper No. 46.

Fineman, M. (2012). 'Beyond Identities: The Limits of an Antidiscrimination Approach to Equality.' In Boston University Law Review, 92(6): pp. 1713-1770.

Fineman, M. (2010). 'Vulnerable Subject and Responsive State.' In Emory Law Journal, Vol. 60, Public Law \& Legal Theory Research Paper Series, Research Paper No. 10-130: pp. 251275.

Goldstein, H. (1979). 'Improving Policing: A Problem-Oriented Approach.' In Crime and Delinquency, 25: pp. 236-258. 
Green, S. (2007). 'Crime, Victimisation and Vulnerability.' In Walklate, S. (2007). Handbook of Victims and Victimology. Cullompton: Willan.

Harmon, A. (2015). 'Vulnerable Populations.' Salem Press Encyclopaedia, January 2015.

Hales, J., Nevill, C. Pudney, S. \& Tipping, S. (2009). Longitudinal Analysis of Offending, Crime \& Justice Survey 2003-06. London: Home Office.

Higgins, A. and Hales, G. (2016). Police Effectiveness in a Changing World Paper 1. The $\begin{array}{llll}\text { Police } & \text { Foundation. } & \text { COnline } & \text { access: }\end{array}$ foundation.org.uk/uploads/holding/projects/changing_world_paper_1].

HMIC (2016). PEEL: Police Effectiveness 2016: A National Overview [Online access: http://www.justiceinspectorates.gov.uk/hmic/wp-content/uploads/peel-police-effectiveness2016.pdf].

Hurst, S. (2008). 'Vulnerability in Research and Health Care: Describing the Elephant in the Room?' In Bioethics 22(4): pp. 121-202.

Innes, H. and Innes, M. (2013). 'Triangle of Risk.' In Police Professional, $4^{\text {th }}$ April 2013.

Innes, M. and Fielding, N. (2002). 'From Community to Communicative Policing: 'Signal Crimes' and the Problem of Public Reassurance.' In Sociological Research Online, 7(2). [Online access: http://www.socresonline.org.uk/7/2/innes.html]

Kawachi, I., Kennedy, B., and Wilkinson, R. (1999). 'Crime: Social Disorganization and Relative Deprivation.' In Social Science and Medicine, 48(6): pp. 719-731.

Kirby, S. (2013). Effective Policing: Implementation in Theory and Practice. Basingstoke: Palgrave MacMillan.

Lewis, J. and Lewis, S. (2014). 'Processes of Vulnerability in England? Place, Poverty and Susceptibility.' In Disaster Prevention and Management, 23(5): pp. 586-609.

Luna, F. (2009). 'Elucidating the Concept of Vulnerability: Layers Not Labels.' In The International Journal of Feminist Approaches to Bioethics 2(1): pp. 121-139. 
Mack, K., Leiber, M., Featherstone, R. and Monserud, M. (2007). 'Reassessing the FamilyDelinquency Association: Do Family Type, Family Processes, and Economic Factors Make a Difference?' In Journal of Criminal Justice, 35(1): pp. 51-67.

Mechanic, D. and Tanner, J. (2007). 'Vulnerable People, Groups and Populations: Societal View.' In Health Affairs, 26(5): pp. 1220-1230.

Ministry of Justice (2015). Code of Practice for Victims of Crime. [Online access: https://www.gov.uk/government/uploads/system/uploads/attachment_data/file/476900/codeof-practice-for-victims-of-crime.PDF]

Misztal, B.A. (2011). The Challenges of Vulnerability: In Search of Strategies for a Less Vulnerable Social Life. Basingstoke: Palgrave Macmillan.

Noakes, L. and Wincup, E. (2004). Criminological Research. London: Sage.

Nyamathi, A., Koniak-Griffin, D. and Greengold, B.A. (eds) (2007). 'Development of Nursing Theory and Science in Vulnerable Populations Research.' In Annual Review of Nursing, 25(1): pp. 3-25.

Paterson, C. and Best, D. (2015). 'Policing Vulnerability through Building Community Connectors.' In Policing 10(2): pp. 150-157.

Palmer, J., Williams, M., Instone, L., Mee, K. and Vaughan, N. (2012). Climate Change Outcomes in the Rental Sector: Strategies for More Than Adaption. Briefing paper Two, Centre for Urban and Regional Studies.

Rader, N., Cossman, J. and Porter, J. (2012). 'Fear of Crime and Vulnerability: Using a National Sample of Americans to Examine Two Competing Paradigms.' In Journal of Criminal Justice, 40(2): pp. 134-141.

Rader, N. E. and Cossman, J.S. (2011). 'Gender Differences in U.S. College Students' Fear of Others.' In Sex Roles: A Journal of Research, 64(7): pp. 568-581. 
Richie, J. and Lewis, J. (eds) (2003). Qualitative Research Practice: A Guide for Social Science Students and Researchers. London: Sage.

Rogers, C. and Coliandris, G. (2015). 'Seeing Vulnerability.' In Police Professional $3^{\text {rd }}$ Sept 2015 .

Roulstone, A., Thomas, P. and Balderston, S. (eds) (2011). 'Between Hate and Vulnerability: Unpacking the British Criminal Justice System's Construction of Disablist Hate Crime.' In Disability \& Society, 26(3): pp. 351-364.

Schuller, N. (2013). 'Is Crime a Question of Health?' In Safer Communities, 12(2): pp. 86-96. Sparks, R. (1981). 'Multiple Victimization: Evidence, Theory, and Future Research.' In Journal of Criminal Law and Criminology, 72(2): pp. 762-778.

Stanford, S. (2012). Critically Reflecting on Being 'At Risk' and 'A Risk' in Vulnerable People Policing. In Bartkowiak-Théron, I. and Asquith, N. (eds) (2012a). Policing Vulnerability. Sydney: Federation Press.

Wager, N.M. (2015). 'Understanding Children's Non-Disclosure of Child Sexual Assault: Implications for Assisting Parents and Teachers to Become Effective Guardians.' In Safer Communities, 14(1): pp. 16-26.

Williams, E., Norman, J. and Wunsch, D. (2009). 'Too Little Too Late: Assessing Vulnerability.' In Policing, 3(4): pp. 355-363.

Wrigley, A. and Dawson, A. (2016). 'Vulnerability and Marginalized Populations.' In Barrett, D., Ortmann, L.W., Dawson, A., Saenz, C., Reis, A. and Bolan, G. (2016). Public Health Ethics: Cases Spanning the Globe. Springer: Open Access.

Wrigley, A. (2015). 'An Eliminativist Approach to Vulnerability.' In Bioethics 29(7): pp. 478487. 